\title{
Analysis of the sensitivity of the impact resonance frequency test as a tool to determine the elastic properties of bituminous materials
}

\author{
R. Tauste ${ }^{\mathrm{a}}, \bowtie$, F. Moreno-Navarro ${ }^{\mathrm{a}}$, R. Gallego ${ }^{\mathrm{b}}$, M.C. Rubio-Gámez ${ }^{\mathrm{a}}$ \\ a. Laboratory of Construction Engineering (LabIC.UGR), Department of Construction Engineering (ICPI), School of Civil \\ Engineering (ETSICCP), University of Granada, (Granada, Spain) \\ b. Department of Structural Mechanics, School of Civil Engineering (ETSICCP), University of Granada, (Granada, Spain) \\ \rtauste@ugr.es
}

\begin{abstract}
The modulus value of bituminous materials is a key factor in the design of road pavements and the estimation of their life service. This parameter can be measured in laboratory but, unfortunately, this requires the deterioration of the pavement so as the consumption of time and resources. Therefore, this study analyses the feasibility of using impact resonance frequency tests as an alternative to traditional methods for determining the dynamic modulus of bituminous mixtures. The sensitivity of this technique has been studied by analyzing its repeatability and reproducibility, studying the variations in the values measured by modifying the dimensions of the specimens, test temperatures and types of mixture tested. In addition, this non-destructive technique has been compared with other traditional tests used to determine the elastic properties of bituminous materials. The results show that this test could be an interesting tool to characterize the properties and damage state of asphalt layers.
\end{abstract}

KEYWORDS: Modulus of Elasticity; Temperature; Rheology; Aggregate; Characterization

Citation/Citar como: Tauste, R.; Moreno-Navarro, F.; Gallego, R.; Rubio-Gámez, M.C. (2017) Analysis of the sensitivity of the impact resonance frequency test as a tool to determine the elastic properties of bituminous materials. Mater. Construcc. 67 [327], e131. http://dx.doi.org/10.3989/mc.2017.04916

RESUMEN: Análisis de la sensibilidad del ensayo de resonancia por impacto como herramienta para determinar las propiedades elásticas de materiales bituminosos. El valor de módulo de los materiales bituminosos es un factor clave en el diseño de pavimentos y la estimación de su vida de servicio. Este parámetro puede ser medido en laboratorio pero, desafortunadamente, esto requiere deteriorar el pavimento así como el consumo de tiempo y recursos. Por ello, este estudio analiza la viabilidad de usar el ensayo de frecuencia de resonancia mediante impacto como alternativa a los métodos tradicionales para determinar el módulo dinámico de mezclas bituminosas. La sensibilidad de esta técnica se ha estudiado analizando su repetibilidad y reproducibilidad, estudiando variaciones en los valores medidos al modificar dimensiones de probetas, temperaturas y tipos de mezcla ensayados. Además, esta técnica no destructiva se ha comparado con otros ensayos tradicionales empleados para determinar propiedades elásticas de materiales bituminosos. Los resultados muestran este ensayo como una herramienta interesante para caracterizar las propiedades y estado de daño de las capas de asfalto.

PALABRAS CLAVE: Módulo Elástico; Temperatura; Reología; Árido; Caracterización

ORCID ID: R. Tauste (http://orcid.org/0000-0003-0317-6522); F. Moreno-Navarro (http:// orcid.org/0000-0001-6758-8695); R. Gallego (http://orcid.org/0000-0002-7260-0940); M.C. Rubio-Gámez (http:// orcid.org/0000-0002-1874-5129)

Copyright: (C) 2017 CSIC. This is an open-access article distributed under the terms of the Creative Commons Attribution License (CC BY) Spain 3.0. 


\section{INTRODUCTION}

In recent years, an increase in traffic volumes and loads per axel in roads and highways (primarily due to the globalization of commerce), has led to the need to optimize construction and maintenance works. This is also the main reason why new elements such as polymers, crumb rubber or thermal power plant ashes $(1,2)$ are being incorporated into bituminous mixtures, in order to achieve more durable pavements that have minimal impact on economic and social activities. In this respect, determining the degree of deterioration of the materials used in the construction of these infrastructures can be of considerable value when attempting to identify the suitability of these new components and the optimal time to conduct rehabilitation activities. For this purpose, it is critical to know the structural behavior of the pavement as well as the way in which different pathologies can have an impact on the roads during their service life (3).

Along with the thickness of the layer of the bituminous mixture, dynamic modulus is one of the most important factors influencing the structural response of pavements (4). Its importance comes from the natural properties of the material and its ability to represent the stress-strain behavior as a function of the temperature and loading rate (5). In addition, the dynamic modulus is considered to be one of the best indicators of the presence of plastic deformations and cracks in asphalt pavements $(4,6)$, and it can therefore be of use when attempting to ascertain the optimal time to conduct rehabilitation projects.

Given its usefulness, the evaluation of dynamic modulus plays a fundamental role in the design of asphalt pavements. Models such as those developed by Witzack (7) or Hirsch (8), allow for the evaluation of this property based on parameters related to the materials (mineral skeleton, type of binder used, voids content, etc.). However, when evaluating pavement deterioration, this parameter is used rather less extensively during the service life when compared with the design phase. Similar concepts such as the measurement of the pavement deflections have been used in order to monitor the degradation of the pavement structure and to ascertain when repairs are needed. However, this parameter cannot make distinctions between the different layers of the infrastructure (foundation layers and pavement), and their results might not only be linked to the bituminous materials. And whilst it might be possible to conduct preliminary testing of cores extracted from the asphalt layers using standard laboratory methods $(9,10)$, this approach has some drawbacks such as the potential degradation of the asphalt layer (caused by the drilling of the pavement to extract the core) or the amount of time and resources consumed (the cores must be transported to the laboratory), all of which render the process non-competitive.
Thus, the use of non-destructive methods (such as the impact resonance frequency test) could provide an alternative to determine the damage that occurs in bituminous materials during their service life in the pavement. One advantage of these tests is that they do not damage the properties of the materials, and they are effective in saving time and resources. In addition, the measures involved in these methods are significantly faster, simpler in their execution, and require relatively low-cost equipment that can offer a high level of repeatability without requiring the production of a large number of samples (11). These tests have also been widely used in many other fields, such as metals and cement concrete. For instance, in the field of asphalt materials, previous studies $(6,12$, 13) have explored the application of this type of testing on cylindrical specimens of bituminous mixtures. These have yielded a good correlation between the values of modulus obtained with the natural resonance frequency tests, and the values obtained with traditional laboratory tests. Furthermore, in recent years, several studies have sought to extend the potential of these tests through the analysis of the signal recorded (14), the use of ultrasonic compression waves "P" or shear waves "S" (15), the measurements of frequency response functions (FRFs) and their correlation with different models such as a finite element computed frequency response. Such studies aimed to improve the estimation of damping properties $(16,17)$, or apply the tests to different geometries such as thin disk specimens (18). In some cases, work was aimed at exploring the possibility of estimating the damage in asphalt mixes $(17,19)$.

Nonetheless, in order to extend the use of these methods to determine the degree of degradation of asphalt pavements on-site, it is necessary to study in more depth the impact of different variables on the relevant measures (such as the dimensions of the sample measured, the temperature of the material, or the type of mixture tested). For this purpose, this paper analyzes the feasibility of applying this type of non-destructive technique to the study of the structural behavior of asphalt pavements by determining the dynamic modulus in prismatic specimens. In particular, the present study will assess the variability of the results in relation to various factors, whilst comparing the findings with those obtained in traditional laboratory tests.

\section{METHODOLOGY}

\subsection{Materials}

The use of non-destructive tests for defining the damage state of asphalt pavements is primarily applied in the surface layer (given that access to the subjacent layers is not possible without degrading the pavement). The present study employed a bituminous mixture commonly used in the surface layers 
of pavements worldwide. Further, given that impact resonance methods tend to be more effective when using homogeneous and continuous media (where the vibrations can be propagated easily and with a clearer signal) mixtures with a lower void content such as those composed of a continuous mineral skeleton (asphalt concrete EN 13108-1) (20), would be the most appropriate. However, since this study aimed to analyze if these methods can be extended to all types of asphalt mixtures, a mixture with a gap-graded mineral skeleton was selected. In particular, a surface layer mixture of the type BBTM11A (UNE-EN 13108-2) (21) was chosen for this study. The mineral skeleton of this mixture was composed of limestone aggregate in the sand fraction $(0 / 6 \mathrm{~mm})$, ophites in the gravel fraction $(6 / 12 \mathrm{~mm})$, and cement in the filler fraction (the mineral skeleton employed can be observed in Figure 1).

In order to evaluate different types of materials, two different mixtures were studied. Both mixtures use the same mineral skeleton as that just described, but they were manufactured with different binders: conventional bitumen B 35/50 (commonly used in low volume traffic roads), and high-performance polymer-modified bitumen BM3c (commonly used in high volume traffic roads and highways). The main characteristics of the binders used (B35/50 and BM3c) and the mixtures designed (BBTM 11A-B35/50 and BBTM 11A-BM3c) are summarized in Tables 1 and 2. As can be observed, the mixtures were designed with very similar characteristics in order to assess if the impact resonance tests are sufficiently precise to reveal differences between quite similar materials.

\subsection{Testing plan}

The main objective of this study is to determine the sensitivity of the natural resonance frequency method for determining the modulus of bituminous mixtures.
For this purpose, it is necessary to control the quality of the signal obtained in the waves, as well as the repeatability and reproducibility of the results, given the variations in the main variables that could affect the measures. Furthermore, to assess the accuracy of this non-destructive test, it is necessary to compare the results with those obtained from other traditional laboratory tests.

The non-destructive method used for studying the materials was an impact resonance test, commonly used for detecting the elastic properties of cement concretes (29). The main components of the test equipment are a hammer that acts as an exciter, an accelerometer (which registers the vibrations caused by the impact of the hammer), a polystyrene support where the specimen is placed (to ensure constant boundary conditions), and a device that analyzes the signal recorded by the accelerometer (Figure 2). The principle of the test is to induce elastic excitation with the hammer in one point of the specimen, and to register the characteristics of the mechanical vibrations caused using the accelerometer in another point of the specimen. These mechanical vibrations are transformed into signals and transferred to the frequency domain by using the fast Fourier transform algorithm (6), in order to determine the resonance frequency of the material. As this parameter is directly related to the stiffness of the material [1], it can be used to define its modulus and to detect the presence of internal defects. In this respect, it is worth noting that bituminous mixtures

TABLE 1. Properties of the binders used in the study

\begin{tabular}{lcc}
\hline Property & B35/50 & BM3c \\
\hline Penetration at $25^{\circ} \mathrm{C}(\mathrm{dmm}, \mathrm{EN} \mathrm{1426} \mathrm{[22])}$ & 44 & 62 \\
Softening Point $\left({ }^{\circ} \mathrm{C}, \mathrm{EN} \mathrm{1427} \mathrm{[23])}\right.$ & 53.2 & 68.4 \\
Fraass Fragility $\left({ }^{\circ} \mathrm{C}, \mathrm{EN} \mathrm{12593} \mathrm{[24])}\right.$ & -8 & -17 \\
\hline
\end{tabular}

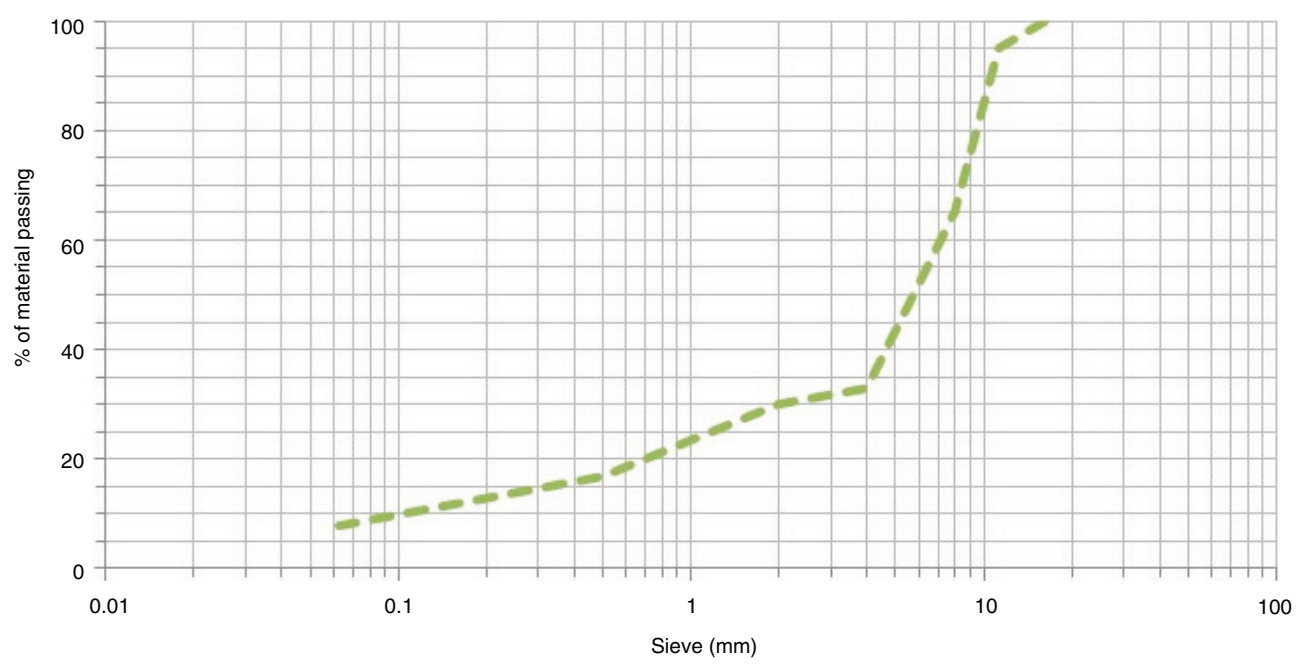

FIgURE 1. Mineral skeleton of the mixture BBTM 11A. 
TABLE 2. Properties of the mixtures designed for the study

\begin{tabular}{lcc}
\hline Property & BBTM 11A-B35/50 & BBTM 11A-BM3c \\
\hline Type of Bitumen & B35/50 & BM3c \\
Bitumen Content (\% over the total weight of the mixture) & 4.8 & 4.8 \\
Bulk Density (g/cm ${ }^{3}$, EN 12697-6 [25]) & 2.496 & 2.464 \\
Air Voids (\%, EN 12697-26, C [26])) & 4.8 & 5.2 \\
Marshall Stability (kN, EN 12697-34 [27]) & 8.662 & 9.301 \\
Marshall Flow (mm, EN 12697-34 [27]) & 3.3 & 3.9 \\
Indirect Tensile Strength at $15^{\circ} \mathrm{C} \mathrm{(kPa,} \mathrm{EN} \mathrm{12697-23} \mathrm{[28])}$ & 1574.6 & 1502.7 \\
\hline
\end{tabular}

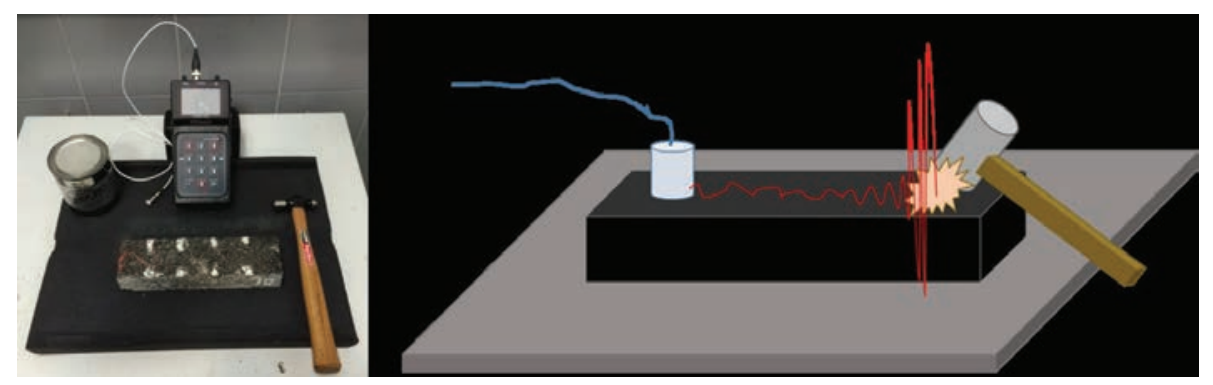

Figure 2. Details of the impact resonance test equipment used, and a sketch of its application.

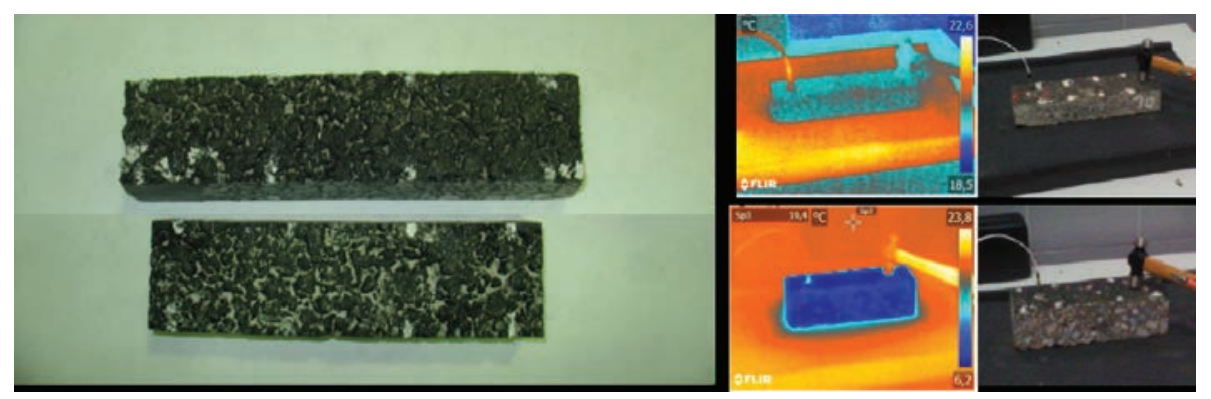

Figure 3. Details of the type of specimens used during this study.

have a certain damping due to their partly viscous nature, and this should be taken into account when determining the resonance frequency. Therefore, the natural frequency $\left(f_{n}\right)$ that will be used in the calculation of the modulus must be calculated from the frequency obtained in the measure $\left(f_{d}\right)$ [2] (13).

$$
E=0.965 \cdot 10^{-6} \cdot\left(\frac{l^{3}}{b \cdot h^{3}}\right) \cdot T \cdot W \cdot f_{n}^{2}
$$

Where $\mathrm{E}$ is the modulus of the material; 1 is the length of the specimen; $b$ is the width of the specimen; $h$ is the height of the specimen; $\mathrm{T}$ is a factor that relates to the length of the specimen and the radius; $W$ is the weight of the specimen; and $f_{n}$ is the resonance frequency.

$$
f_{d}=f_{n} \sqrt{1-\xi^{2}}
$$

Where $\xi$ is the damping factor measured.
As defined, the resonance frequency of a solid material depends on its stiffness, mass, dimensions, and boundary conditions. It therefore follows that the dimensions of the test specimens will influence the measurement of the modulus using the impact resonance test. Consequently, it is necessary to evaluate the impact of this variable on the calculated value of the dynamic modulus, in order to validate the results obtained. For this purpose, two different lengths of specimen were used $(260 \mathrm{~mm}$ and $206 \mathrm{~mm}$ ), maintaining a constant width of $60 \mathrm{~mm}$ and a height of $40 \mathrm{~mm}$ (Figure 3 ). When establishing these sizes, the recommendation included in the standard ASTM-C215 (29) was taken into account, stipulating that the ratio between the length and the largest dimension in the transverse direction must be at least 2:1.

As this method was originally intended for concrete cement specimens, it is necessary to consider certain issues. Firstly, it should be noted that the values obtained with this test correspond to those 
associated with the modulus at high frequencies, due to the high frequencies produced by the impact of the hammer (in the order of $\mathrm{kHz}$ ) (13). Thus, the values obtained cannot directly be compared with those obtained using other laboratory methods such as the stiffness test (9). Secondly, as bituminous mixtures are visco-elastic materials that behave in a more viscous manner as the temperature increases, the test will suffer a loss of quality in the recorded signals under these circumstances (the damping factor depends on the test temperature, reducing its value when the temperature decreases) (6). Therefore, it is necessary to analyze the influence of the test temperature on the calculated value of the modulus obtained with the impact resonance test. The specimens were therefore tested at different temperatures, starting at $-15^{\circ} \mathrm{C}$, and increasing in increments of $5^{\circ} \mathrm{C}$ up to a maximum of $30^{\circ} \mathrm{C}$. The specimens were conditioned for 4 hours at the test temperature before the measurements were taken, and the temperature was controlled with an infrared camera during the test (Figure 3 ). In addition, the vibrations transmitted with the impact of the hammer will depend on the type of material used, thus making it worthwhile to evaluate two different types of bitumen (B35/50 and BM3c).

Twelve specimens of each type of mixture (BBTM 11A-BM3c and BBTM11A-B35/50) were tested at the different temperatures, six with a length of $260 \mathrm{~mm}$ and another six with a length of $206 \mathrm{~mm}$. Each specimen was tested twenty times at each temperature. Thus, the analysis of sensitivity of the impact resonance test for the measurement of the modulus of bituminous mixtures was evaluated as a function of the main variables that could affect the results (size of the specimen, temperature, and type of material). For this purpose, the repeatability (variations obtained in the measurements made in a given specimen under the same test conditions) and reproducibility (variations obtained in the measurements made in different specimens of the same material under the same test conditions) of the test was evaluated using the coefficient of variation [3].

\section{Coefficient of Variation,}

$$
C V(\%)=\frac{\text { Standard deviation }}{\text { Average value }} * 100
$$

Finally, in order to compare the results obtained in the impact resonance test, a different laboratory method was used to calculate the modulus of the bituminous materials. Given that the only difference between the mixtures was the type of binder used in their manufacture (they were manufactured with the same mineral skeleton and quantity of bitumen), along with the fact that a direct correlation between the characteristics of the binder and the mixture has been demonstrated (30), two different modulus tests were conducted on the binders (B35/50 and BM3c).

In one test, the modulus was tested through the rheological response of the binders, analyzed using the frequency sweep test at various temperatures $\left(10,20,30^{\circ} \mathrm{C}\right)$ This test was carried out using the Dynamic Shear Rheometer (DSR - see Figure 4a) where an oscillatory shear loading was applied at constant amplitude ( $0.1 \%$ strain $)$ and at a frequency of $5 \mathrm{~Hz}$. During the tests, the complex shear modulus $\left(\mathrm{G}^{*}\right)$ was recorded (EN 14770).

In the other test, the modulus was measured under tensile strain conditions $(0.1 \%$ of strain at $10 \mathrm{~Hz}$ at $-5^{\circ} \mathrm{C}, 5^{\circ} \mathrm{C}$, and $10^{\circ} \mathrm{C}$ ) using a dynamic press (Figure 4b). In addition, the stiffness modulus of the mixtures was also determined at different temperatures $\left(10^{\circ} \mathrm{C}, 20^{\circ} \mathrm{C}\right.$ and $\left.30^{\circ} \mathrm{C}\right)$ using the indirect tensile (IT) test described in the standard EN 12697-26, Annex C (Figure 4c). The test samples were cylinders, which had a thickness of 30-75 $\mathrm{mm}$ and a diameter of $101.6 \pm 0.1 \mathrm{~mm}$, and manufactured with an impact compactor (UNE-EN 12697-30). The specimens were stored at a temperature of $5^{\circ} \mathrm{C}$ and then allowed to adjust to the test temperature $\left(10^{\circ} \mathrm{C}, 20^{\circ} \mathrm{C}\right.$ and $\left.30^{\circ} \mathrm{C}\right)$. After placing and securing the specimen in a vertical position at one of its diameters, 10 load pulses were applied so that the device could adjust to the magnitude of the load and its duration. In order to measure
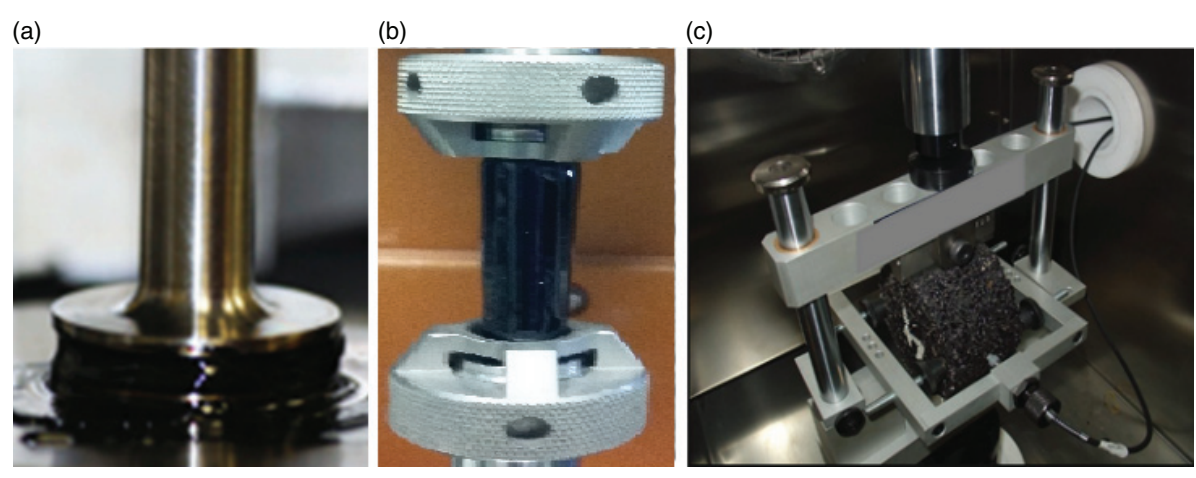

FIGURE 4. Detail of the different laboratory tests used to compare the results obtained in the impact resonance test. 
the deformation of the diameter, 5 additional load pulses were applied to measure and record the load variation and deformation in the time period of each pulse. At the same time, the surface load factor was also determined. As a result, the stiffness modulus was obtained for two diameters of the specimen (forming an angle of $90 \pm 10^{\circ}$ ).

\section{ANALYSIS OF RESULTS}

The results from the analysis of the quality of the signal recorded under different test conditions (temperature, mixture type, and size of the test specimen) are shown in Figure 5. For evaluation purposes, the test equipment supplied a quality index ranging between 1 and 9 (the latter value indicating the highest signal quality).

Figure 5 (where the average values obtained in the different mixtures are compared) shows a decline in the quality of the signal obtained on the resonance test as the test temperature increased (regardless of the size of the specimen used). This implies a possible limitation of this test method, since rates below 4 indicates that the acquired signal is not sufficiently accurate and the value of the modulus could not be representative. Thus, at least for the mixtures tested here, it could be argued that measurements over $30^{\circ} \mathrm{C}$ might not be reliable and are therefore not to be recommended (as at these temperatures, the mixtures reached values close to 4). Values between 8 and 9 can be considered as the most appropriate to take the measurements, and they were obtained at a temperature of approximately $5^{\circ} \mathrm{C}$ in the case of the mixture manufactured with the BM3c, and approximately $10^{\circ} \mathrm{C}$ in the case of the mixture manufactured with the B35/50. Comparing the sizes of the specimens suggests that as the size decreases, the quality of the signal also decreases (nonetheless, the impact of this variable is lower than that caused by the test temperature). Finally, a comparison of the two types of mixtures reveals that the mixture manufactured with the B 35/50 has a better quality of signal than that manufactured with the BM3c. This could be due to a stiffer response of the mixture (caused by the type of binder, which has a lower penetration grade), which allows it to perform more elastically. In this case, it is possible that mixtures with a higher stiffness (for example those manufactured with a low penetration binder) can be evaluated at higher temperatures.

Figure 6 shows the errors of the measurements in terms of the repeatability of the test, during assessment of the modulus using the impact
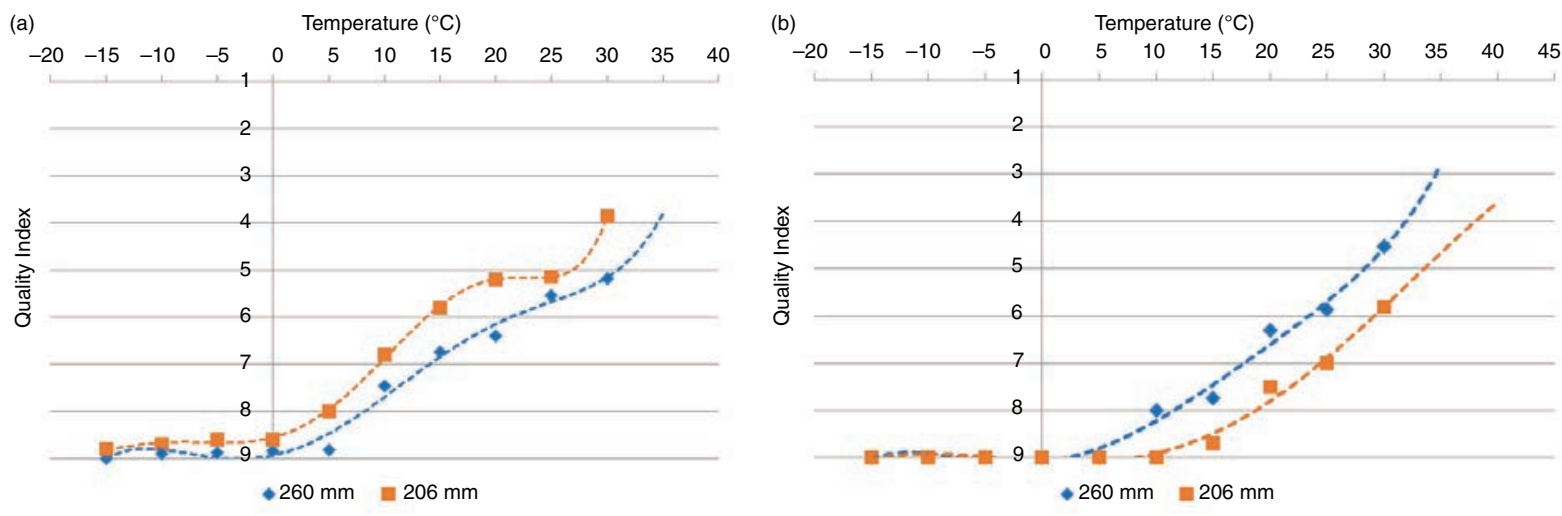

Figure 5. Evolution of quality signal of the samples of BBTM 11B-BM3c (a), and BBTM 11A-B35/50 (b).
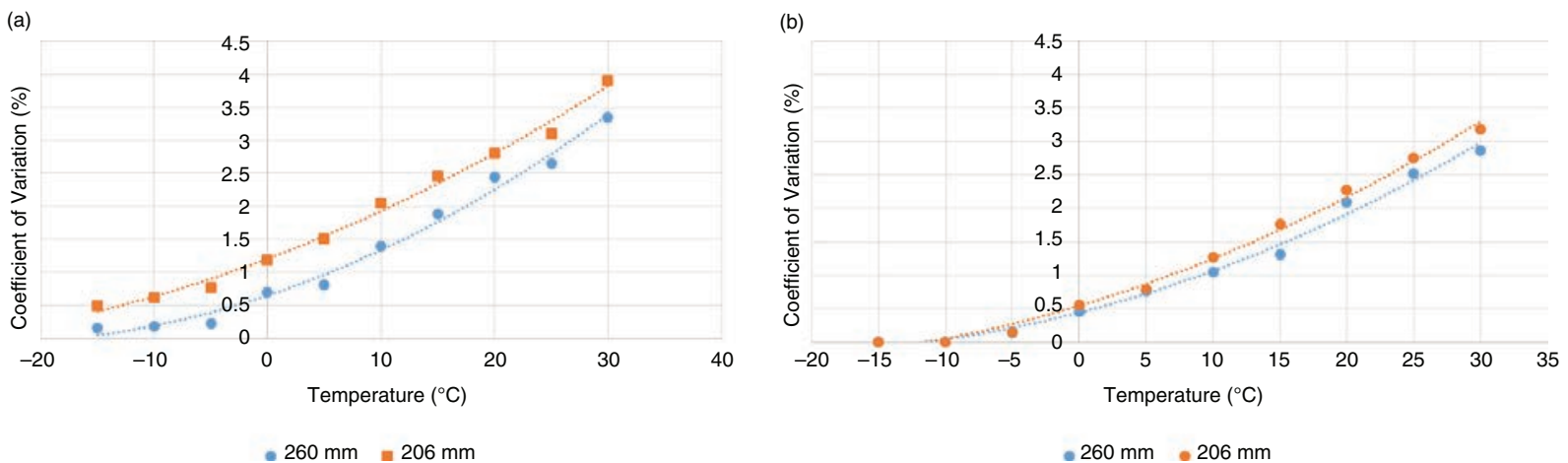

FIGURE 6. Average results of the repeatability of impact resonance test in the mixtures studied: BBTM 11B-BM3c (a), and BBTM $11 \mathrm{~A}-\mathrm{B} 35 / 50$ (b). 
resonance method. As with the case of signal quality, it was found that as the temperature increased and the stiffness of the mixture decreased, the repeatability of the test decreased (which is due to a more viscous behavior that induces an increase in the damping of the vibration), and therefore the resulting measurement can be considered less reliable. This effect is clearly observed regardless of the size of the specimen, which is the variable that least affects the measurements made. This conclusion is in accordance with other studies that also show that the different dimensions of the specimens did not affect the modal test results in cylindrical geometries unless they had a thickness of less than 4 centimeters $(16,17,18,19)$. Nonetheless, it should be pointed out that for the mixtures tested and the temperature used here, the obtained values have high repeatability, suggesting that the resonance impact test is suitable for assessing changes in the modulus of bituminous mixtures. In any case, in order to correctly apply this method and achieve reliable measures, it is necessary to control some factors such as the test temperature and the type of binder used.

Figure 7 shows the reproducibility of the method, measured using the coefficients of variation obtained from the various tests with different specimens having the same geometry (length of $206 \mathrm{~mm}$ ). Once again, the effect of damping reduces confidence in the results obtained with this method (the reproducibility of the method decreases with an increase in temperature and a decrease in the stiffness of the mixture). Nonetheless, the results obtained for the mixtures and temperatures tested here show an acceptable value of reproducibility in the calculus of the stiffness modulus, if they are compared with the results obtained in other laboratory tests.
Figure 8 shows, for the various specimens of the two mixtures, the average results of the stiffness modulus obtained as a function of the temperature (calculated using the impact resonance test). The value of the modulus appears to decrease as the temperature increases, regardless of the size of the specimen and the type of bituminous mixture. This trend is in accordance with the results of mechanical tests performed on both the binders (DSR and tension-compression tests) and mixtures (indirect tensile stiffness tests), where the modulus of the bituminous materials also decreases as a function of the temperature. These results also confirm that the weaker the relationship between the length and the width of the sample, the higher the value of the modulus obtained. In this regard, it should be pointed out that higher values of modulus were found in the mixture manufactured with the bitumen B35/50, which is in line with the results obtained in the laboratory tests conducted on the binders and mixtures, and also confirms the viability of using this method to compare different types of mixtures.

Figure 9 displays the relationship between the values obtained in the non-destructive test and the laboratory tests conducted on the binders and mixtures. The values of modulus obtained vary between the different methods, since the non-destructive test applies frequencies that are considerably higher than those used in the laboratory tests, and these tests are therefore not comparable. This is something characteristic of the test, which occurs systematically, particularly at higher temperatures, as found in several studies $(15,16,19)$. Thus, higher values are obtained when determining the modulus with the impact resonance test (it should be pointed out that the values obtained from different laboratory

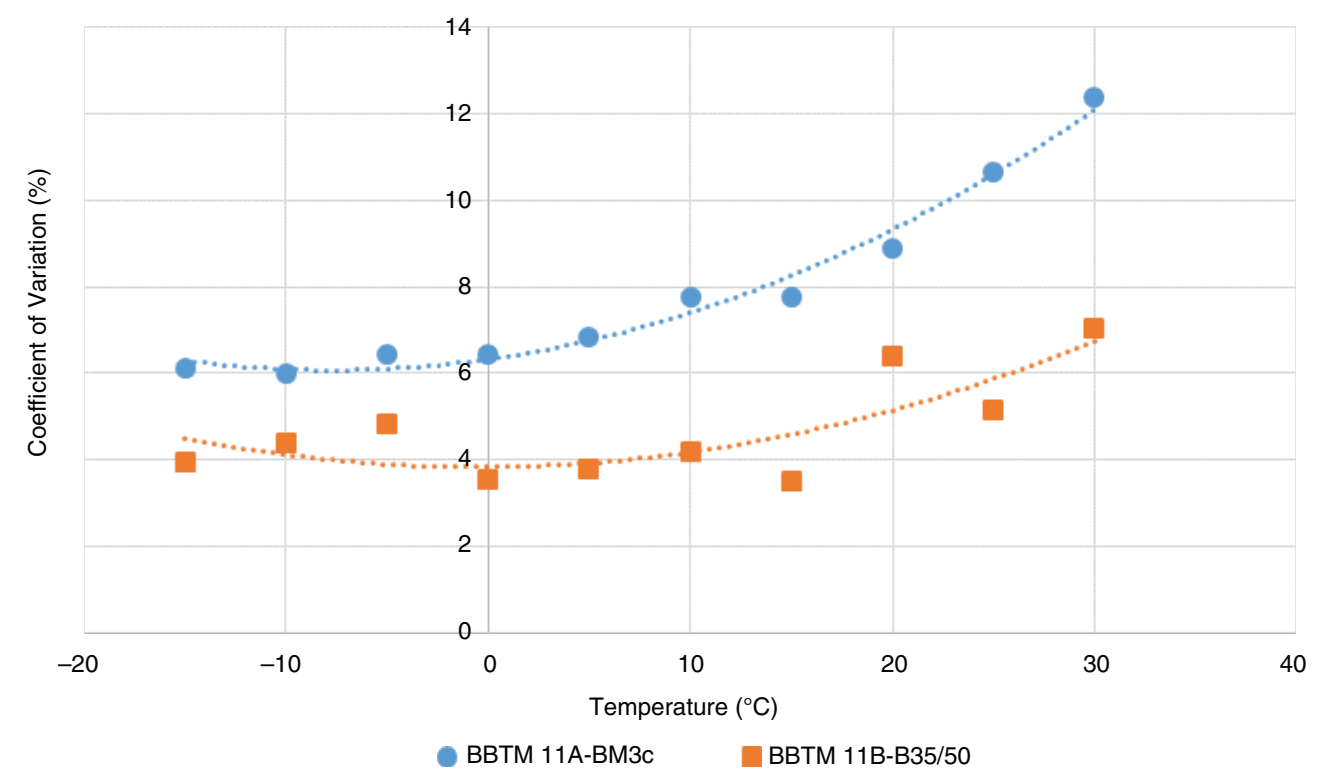

FIGURE 7. Average results of the reproducibility of the impact resonance test in the mixtures studied. 
(a)

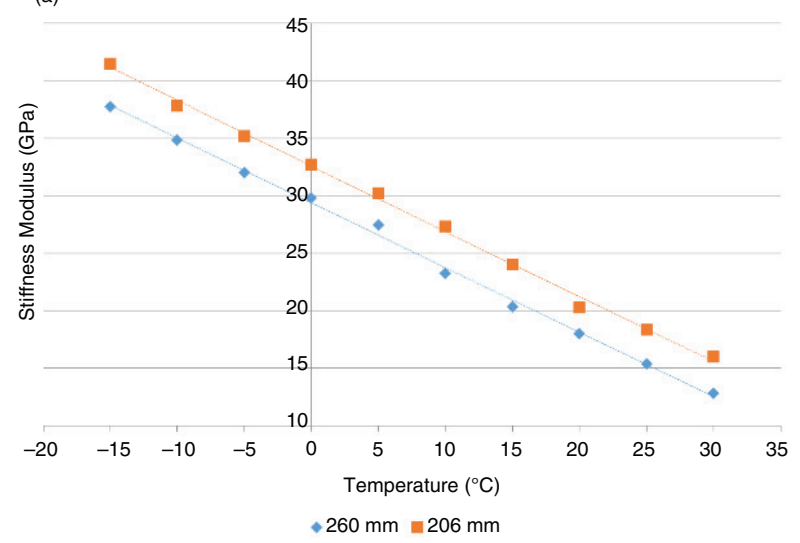

(b)

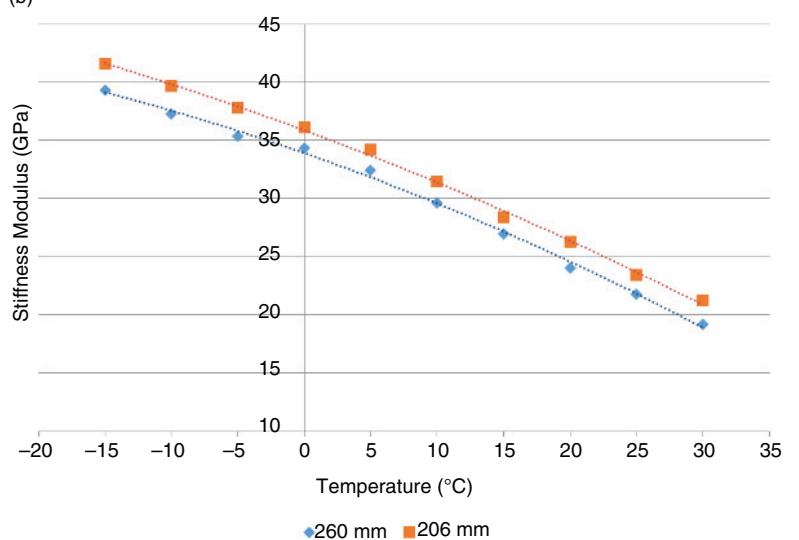

FIGURE 8. Stiffness modulus results obtained with the impact resonance frequency test.
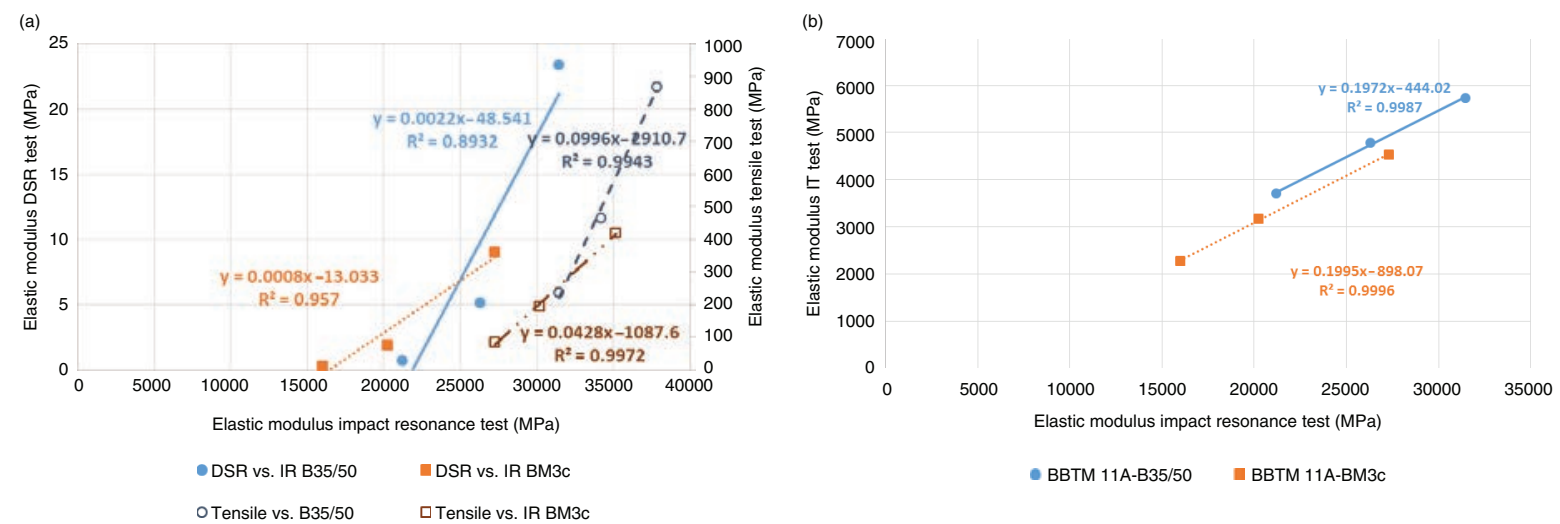

FIGURE 9. Relationship between binder laboratory tests (a), bituminous mixture laboratory test (b), and the impact resonance frequency test.

methods are also not comparable, since they apply different types of efforts and frequencies). However, it is worth nothing that, in the present study, there is a high linear correlation between the values obtained at different temperatures and with the different methods employed. This result provides support for the use of non-destructive tests as a tool to identify the changes in the modulus produced in asphalt materials in order to monitor alterations in their mechanical properties without damaging the infrastructure.

\section{CONCLUSIONS}

This paper analyses the application of a nondestructive test (impact resonance frequency) for evaluating the elastic properties of bituminous materials. This analysis involved studying the main variables that can affect the measurements made with this method, as well as their repeatability and reproducibility. Furthermore, the results obtained with the impact resonance test were compared with those from other traditional laboratory tests.
The main conclusions obtained in this research study can be summarized as follows:

- Given that bituminous mixtures are visco-elastic materials, the measurement of their modulus using the impact resonance test can be highly influenced by the damping of the vibrations. It has been demonstrated that some variables such as the temperature or the type of bitumen could play an important role in determining the accuracy of this method in assessing the modulus of an asphalt layer. The results obtained for the materials studied here suggest that, regardless of the type of bitumen used, for temperatures between 0 and $10^{\circ} \mathrm{C}$ the impact resonance test has shown to be a reliable method for determining the elastic modulus of bituminous layers.

- The size of the specimen could affect the values of the elastic modulus. Nonetheless, it was shown that the impact of a variation of more than $5 \mathrm{~cm}$ does not considerably affect the measurement, or its quality. In this respect, the variations in the size produced during the manufacture of 
the specimens in the laboratory (which have an order of $\mathrm{mm}$ ) can be disregarded, as they will not affect the measures taken with this method.

- $\quad$ Based on the conclusions previously described, the impact resonance frequency test appears to have good repeatability and reproducibility, and could therefore be used as a substitute for traditional laboratory tests to determine the elastic properties of bituminous materials and to ascertain their damage state. It is also worth noting that this non-destructive test can be applied more rapidly than traditional laboratory tests and thus has the potential to save time and economic resources when evaluating these materials.

- The impact resonance frequency test has sufficient precision to characterize the elastic parameters of bituminous mixtures that have very similar properties. This feature is of interest, as this tool could be used to monitor the changes produced in an asphalt pavement due to the development of damage.

- Finally, it is important to note that comparing the impact resonance frequency test results with those of other traditional laboratory tests reveals a high correlation between them. This finding suggests the potential for using this method to determine the elastic properties of these materials. Nonetheless, it is necessary to remember that as the frequency of the impact is very high, the modulus values calculated are considerably higher than those obtained in the laboratory tests.

\section{REFERENCES}

1. Jiménez del Barco-Carrión, A.; García-Travé, G.; MorenoNavarro, F.; Martínez-Montes, G.; Rubio-Gámez, M.C. (2016). Comparison of the effect of recycled crumb rubber and polymer concentration on the performance of binders for asphalt mixtures. Mater. Construcc. 66[323]. http:// dx.doi.org/10.3989/mc.2016.08815

2. López-López, E.; Vega-Zamanillo, A.; Calzada-Pérez, M.A.; Taborga-Sedano, M.A. (2015). Use of bottom ash from thermal power plant and lime as filler in bituminous mixes. Mater. Construcc. 65[318]. http://dx.doi.org/10.3989/ mc. 2015.01614

3. Moreno, F. (2013). Diseño de un método de ensayo de laboratorio para el análisis de la resistencia a fisuración de mezclas bituminosas. Phd thesis. Universidad de Granada.

4. Garcia, G.; Thompson, M. (2007). HMA dynamic modulus - temperature relations. Research Report FHWAICT-07-006, Illinois Center for Transportation.

5. Moreno-Navarro, F.; Sol-Sánchez, M.; Rubio-Gámez, M.C. (2015). The effect of polymer modified binders on the long-performance of bituminous mixtures. Mater. Design. 78, 5-11. http://dx.doi.org/10.1016/j.matdes.2015.04.018

6. Kweon, G.; Kim, Y.R. (2006). Determination of asphalt concrete complex modulus with impact resonance test. Transport. Res. Rec. 1970, 151-160. http://dx.doi.org/10.3141/1970-18

7. Witzack, M.W. (2005). Simple Performance Tests: Summary of Recommended Methods and Database. Transport. Res Board. 547. National Cooperative Highway Research Program.

8. Mateos, A.; Soares, J. (2015). Validation of a dynamic modulus predictive equation on the basis of Spanish asphalt concrete mixtures. Mater. Construcc. 65[317] http://dx.doi. org/10.3989/mc.2015.01114
9. AENOR, (2012). UNE-EN 12697-26. Bituminous mixtures - Test methods for hot mix asphalt - Part 26: Stiffness, Asociación Española de Normalización y Certificación, (in Spanish), On line at:http:/www.aenor.es/aenor/normas/ normas/fichanorma.asp?tipo $=\mathrm{N} \& \operatorname{codigo}=\mathrm{N} 0050271 \mathrm{\#}$. WBt7MSTD47s

10. AASHTO T342, (2011). Standard Method of Test for Determining Dynamic Modulus of Hot Mix Asphalt (HMA). American Association of State Highway and Transportation Officials.

11. Gudmarsson, A. (2012). Laboratory seismic testing of asphalt concrete. Phd. KTH Royal Institute of Technology School of Architecture and Built Environment. Department of Transport Science. Division of Highway and Railway Engineering.

12. Whitmoyer, S.; Kim, Y.R. (1994). Determining asphalt concrete properties via the impact resonant method. J. Test. Eval. 22[2], 139-148. https://doi.org/10.1520/JTE12648J

13. Ryden, N. (2011). Resonant frequency testing of cylindrical asphalt samples. Eur. J. Environ. Civ. En. 15[4-4], 587-600. http://dx.doi. org/10.3166/EJECE.15.587-600

14. Mun, S. (2015). Determining the dynamic modulus of a viscoelastic asphalt mixture using an impact resonance test with damping effect. Res. Nondestruct. Eval. 26[4]. http:// dx.doi.org/10.1080/09349847.2015.1023914

15. Mounier, D.; Di Benedetto, H.; Sauzéat, C. (2012). Determination of bituminous mixtures linear properties using ultrasonic wave propagation. Constr. Build. Mater. 36, 638-647. http://dx.doi.org/10.1016/j. conbuildmat.2012.04.136

16. Gudmarsson, A.; Ryden, N.; Di Benedetto, H.; Sauzéat, C. (2015). Complex modulus and complex Poisson's ratio from cyclic and dynamic modal testing of asphalt concrete. Constr. Build. Mater. 88, 20-31. http://dx.doi.org/10.1016/j. conbuildmat.2015.04.007

17. Gudmarsson, A. (2014). Resonance testing of asphalt concrete. Phd thesis. KTH Royal Institute of Technology School of Architecture and the Built Environment, Stockholm.

18. Kim, D. (2015). Modulus and Permanent Deformation Characterizat.ion of Asphalt Mixtures and Pavements. Phd thesis. North Carolina State University.

19. Zhang, L.; Tian-shuai, L.; Yi-qiu Tan. (2016). The potential of using impact resonance test method evaluating the anti-freeze-thaw performance of asphalt mixture. Constr. Build. Mater. 115, 54-61. http://dx.doi.org/10.1016/j. conbuildmat.2016.04.026

20. AENOR, (2008). UNE-EN 13108-1. Bituminous mixtures, Material Specifications - Part 1: Asphalt Concrete, Asociación Española de Normalización y Certificación, (in Spanish), On line at:http://www.aenor.es/aenor/normas/ normas/fichanorma.asp?tipo $=\mathrm{N} \& \operatorname{codigo}=\mathrm{N} 0042341 \&$ pdf=\#.WB21JiRfaSo

21. AENOR, (2007). UNE-EN 13108-2. Bituminous mixtures, Material Specifications - Part 2: Asphalt Concrete for Very Thin Layers, Asociación Española de Normalización y Certificación, (in Spanish), On line at: http://www.aenor.es/aenor/normas/normas/fichanorma. asp?tipo $=\mathrm{N} \&$ codigo $=\mathrm{N} 0040015 \# . \mathrm{WB} 21 \mathrm{WSR}$ faSo

22. AENOR, (2015). UNE- EN 1426. Bitumen and bituminous binders. Determination of needle penetration, Asociación Española de Normalización y Certificación, (in Spanish), On line at: http://www.aenor.es/aenor/normas/ normas/fichanorma.asp?tipo $=\mathrm{N} \& \operatorname{codigo}=\mathrm{N} 0055820 \#$. WB23CCRfaSo

23. AENOR, (2015). UNE-EN 1427. Bitumen and bituminous binders. Determination of the softening point - Ring and ball method, Asociación Española de Normalización y Certificación, (in Spanish), On line at: http://www.aenor. es/aenor/normas/normas/fichanorma.asp?tipo $=$ N\&codigo $=\mathrm{N} 0055821 \& \mathrm{pdf}=\#$.WB26CiRfaSo

24. AENOR, (2015). UNE-EN 12593. Bitumen and bituminous binders. Determination of the Fraass breaking point, Asociación Española de Normalización y Certificación, (in Spanish), On line at: http://www.aenor.es/aenor/normas/ normas/fichanorma.asp?tipo $=\mathrm{N} \& \operatorname{codigo}=\mathrm{N} 0055822 \mathrm{\#}$. WB26zCRfaSo 
25. AENOR, (2012). UNE-EN 12697-6. Bituminous mixtures. Test methods for hot mix asphalt - Part 6: Determination of bulk density of bituminous specimens, Asociación Española de Normalización y Certificación, http:// www.aenor.es/aenor/normas/normas/fichanorma. asp?tipo $=$ N\&codigo $=$ N0049868\#.WB27yyRfaSo

26. AENOR, (2003). UNE-EN 12697-8. Bituminous mixtures. Test methods for hot mix asphalt - Part 8: Determination of void characteristics of bituminous specimens, Asociación Española de Normalización y Certificación, (in Spanish), On line at: http://www.aenor.es/aenor/normas/normas/fichanorma.asp?tipo $=\mathrm{N} \& \operatorname{codigo}=\mathrm{N} 0030158 \#$. WB28JiRfaSo

27. AENOR, (2013). UNE-EN 12697-34. Bituminous mixtures. Test methods for hot mix asphalt - Part 34: Marshall test, Asociación Española de Normalización y Certificación, (in Spanish), On line at: http://www.aenor.es/aenor/normas/ normas/fichanorma.asp?tipo $=\mathrm{N} \& \operatorname{codigo}=\mathrm{N} 0050744 \&$ pdf $=\#$.WB281iRfaSo

28. AENOR, (2004). UNE-EN 12697-23. Bituminous mixtures. Test methods for hot mix asphalt - Part 23: Determination of the indirect tensile strength of bituminous specimens, Asociación Española de Normalización y Certificación, On line at: http://www.aenor.es/aenor/normas/normas/fichanorma .asp?tipo $=\mathrm{N} \&$ codigo $=$ N0030534\#. WB29jyRfaSo

29. ASTM C 215, (2014). Standard test method for fundamental transverse longitudinal and torsional resonant frequencies of concrete specimens. American Society for Testing and Materials (ASTM)

30. Moreno-Navarro, F.; Sol-Sánchez, M.; Jimenez del Barco, A.; Rubio-Gámez, M.C. (2015). Analysis of the influence of binder properties on the mechanical response of bituminous mixtures. Int. J. Pavement Eng. http://dx.doi.org/10.10 $80 / 10298436.2015 .1057138$ 